\title{
Juvenile Offenders: Suspension of Trial and "Probationary Period". A Study on Re-Educational Role of Social Service in Italy
}

\author{
Nicola Malizia \\ Associate Professor of Sociology of Law, Deviance and Social Change, Faculty of Sciences of Man and Society, \\ University of Enna “Kore”, Enna, Italy \\ Email: nicola.malizia@unikore.it
}

How to cite this paper: Malizia, N. (2021). Juvenile Offenders: Suspension of Trial and "Probationary Period". A Study on Re-Educational Role of Social Service in Italy. $A d$ vances in Applied Sociology, 11, 130-140. https://doi.org/10.4236/aasoci.2021.113010

Received: March 5, 2021

Accepted: March 28, 2021

Published: March 31, 2021

Copyright ( 2021 by author(s) and Scientific Research Publishing Inc. This work is licensed under the Creative Commons Attribution International License (CC BY 4.0).

http://creativecommons.org/licenses/by/4.0/ (c) (i) Open Access

\begin{abstract}
The aim of this study is to investigate the institution of the "probationary period" for juvenile offenders in Italy, after the suspension of criminal proceedings. The aim of this alternative measure to detention is to re-educate and resocialise minors who have entered the criminal circuit, avoiding traumatic contact with prison and the reiteration of criminal conduct. The data collection was carried out through the cooperation of the Italian Juvenile Service Offices and the Ministry of Justice. The statistical method used Mathlab R2020b made it possible to process data from 2010 to 2020 to quantify criminal conduct, types and specificity of offences committed by Italian and foreign minors (both male and female), as well as to verify the effectiveness of probation. The positive results exceed $80 \%$ and demonstrate the effectiveness of the "probationary period" instrument in the process of re-education and re-socialisation of juvenile offenders.
\end{abstract}

\section{Keywords}

Juveniles, Crimes, Social Service, Criminal Justice, Re-Education

\section{Introduction}

Caraccioli (2018) outlines the juvenile entry phase into criminal circuit, which begins with the drafting of a report by the judicial police containing the news of the crime; the start of the process (during which the minor will still be followed by Social Services) is the consequence, therefore, of the arrest, the detention, or the "complaint on the loose". The Public Prosecutor, may order the accompaniment of the minor to the Centre of First Reception, his placement in a Com- 
munity authorised by the Ministry of Justice (D'Onofrio \& Trani, 2011), or establish that the minor is taken to his parents' house, after a transmission of a report of the crime. The Public Prosecutor will recommend his parents to keep him available for the investigations. The First Reception Centre (C.P.A.), with the support of a multidisciplinary team, hosts the arrested, detained or accompanied minors for a maximum period of ninety-six hours and in any case until the validation hearing of the arrest. The team's task is to gather initial information on the minor's personal, family and social condition, and to identify initial intervention hypotheses. Data and other information on the minor will be collected in a report, sent to the judge and the prosecutor at the validation hearing. Within the first forty-eight hours, the Public Prosecutor asks the Judge for Preliminary Investigations (G.I.P.) to validate the arrest (detention or accompaniment). The Judge for Preliminary Investigations (G.I.P.) can validate or not the arrest by ordering the application of a precautionary measure among those provided for by Articles 20-21-22-23 of the Presidential Decree 448/88 or the release. Precautionary measures are established in order to protect the community (danger of evidence pollution, flight or reiteration of serious crimes) (Biarella, 2017). When the judge orders a precautionary measure, he entrusts the defendant to the Ministerial Social Services, which, in agreement with the minor, plan a treatment programme that may involve study, work, volunteering or other activities; the purpose of non-custodial precautionary measures is to promote the social reintegration of the minor. The purpose of non-custodial precautionary measures is to promote the social reintegration of the minor. Through their intervention, the Social Services support and monitor the minor, provide the judge with further elements for the assessment of the case; clarify to the minor and his family the meaning of the measure, witness the evolution of the minor and the activated processes of change (Ciaschini, 2012). The precautionary measures (Giostra, 2016) referred to in the D.P.R.448/88 are: prescriptions (art. 20), home detention (art. 21), community placement (art. 22) and pre-trial detention (art. 23).

1) Prescriptions (Art. 20): prescriptions are in first place (because of their lesser afflictiveness) because they give the minor positive reinforcements that help him/her in the restructuring of his/her personality. The minor is motivated to perform specific tasks aimed at fostering the growth of self-esteem and personal enrichment (obligations or prohibitions concerning study, work or other activities useful for his/her education). In case of serious and repeated violations, the Judge may order the measure of the next higher level, i.e. home detention (Art. 21).

2) Home detention (art.21): during the home detention, the juvenile services have the task of monitoring the progress of the measure and of requesting any changes to the Judicial Authority, in compliance with the minor's needs and the ongoing educational processes. The obligation is to set the minor at the family home or another private residence after assessing the existing relationship between the minor and his family environment. In this case, it is very important 
either for the judge to have direct knowledge of the minor's environment, directly or through the social services. The measure, in fact, is usually used when there are favorable family conditions that guarantee the minor to continue his educational processes. If the family is unsuitable to carry out the task, i.e. to supervise the activities of the minor and to cooperate with the Services (or there are serious problems of different nature), the Judge may order the execution of the measure in a public or conventional Community.

3) Placement in a Community (art. 22): the minor is obliged to stay in a public community or in one that has an agreement with the competent Region dealing with juvenile problems and with a family organization, (the minor is not allowed to leave the community unless authorized by the Judge to carry out activities useful for his/her education). Within the community, the minor, supervised by social workers and educators, may participate in recreational and work activities and school support, based on personalized intervention plans and in accordance with his needs. Also in the Community, the minor may be required to carry out any prescriptions.

4) Precautionary custody in prison (art. 23): it's used for crimes that need life imprisonment or imprisonment of not less than nine years, and when there are proceedings for crimes of rape. In addition to these cases, it is applied as an aggravation of the placement in the Community (for a maximum of one month) and again, if there are serious and compelling needs relating to the investigation, and when any other measure is inadequate. At the end of the preliminary investigation phase, if the case is not dismissed, the Public Prosecutor files the request for committal to trial with the clerk of the Judge for the Preliminary Hearing (G.U.P., collegial body). Bartoli (2020), argues that the Italian measure of "suspension of trial and probation of juvenile offender" draws its origin from the Anglo-Saxon "probation system". However, it presents a relevant difference: In the United Kingdom, "probationary period" is conceived as an alternative measure to "punishment" and, therefore, posterior to the sentence of condemnation. In the Italian system, on the other hand, it takes place during the trial and, for this reason, is defined as a form of "trial probation" which translates into an instrument of "determination of the fact" and into a concrete action of "intervention on the personality of the defendant", for the purpose of "recovering, educating and socializing the minor". The commitment of the young person who intends to change his/her behavior corresponds, in fact, to the renunciation by the State of the same sentence and the continuation of the process (Biarella, 2017). It is appropriate to highlight the differences between probation and diversion, given that the institution of "probationary period" in Italy can reasonably be considered a hybrid of these two models. Diversion (absent in the Italian legal system) consists in the removal of the child from the judicial circuit at the very moment in which the suspicion of his or her responsibility for the act arises, and in any case before the criminal prosecution is formally exercised and the child is entrusted to the welfare bodies. 


\section{Literature Review}

According to Biarella (2017), weather the advantage of this procedure is to avoid the contact of the juvenile with the judicial authority organs; the disadvantage is that of a lack of awareness of the fact caused by the perpetrator. On the other hand, according to Randazzo \& Galati, (2020) probation, is an alternative instrument to detention, following a conviction. Therefore, is not elusive of the consequences related to a decisive measure of ascertainment of responsibility; it is aimed at avoiding the aspects of the prison experience to the minor that could have a devastating impact on him/her, and is applicable within a legally predefined framework. According to Di Tullio D'Elisiis (2016) the institution of "probationary period" incorporates the positive aspects of both institutions. Unlike diversion, the juvenile is supervised by judicial authority at all stages which takes note of the social disvalue linked to the criminal act. Compared to probation, however, it has the advantage of being able to apply this institution to any type of crime, also avoiding the devastating effects of the conviction since, the "probationary period" is applied before the Judge's pronouncement, and, in case of positive outcome, it extinguishes the crime committed, without the need to reach the conviction itself. Macrillò (2018) argues that, to date, the institution of the trial suspension, with consequent "probationary period" consists in, undoubtedly, the fulcrum of the entire Italian penal procedural reform in the juvenile sector, taking into account the personality of these subjects still in evolution. Therefore, the examination of the minor's personality becomes central as a means to understand the real meaning of the deviant act committed. In fact, the actual need is to perceive whether the criminal act reflects a "constant and habitual way of being" of the subject or whether it is rather to be set within a merely occasional conduct. The aim is to avoid the juvenile from falling into the drama of criminal proceedings, which could cause irreversible damage to individuals who are still fragile, immature and in a phase of personality construction (Senigaglia, 2020). On the other hand, an erroneous assessment of the offender's personality, as well as an overly rigorous and intransigent attitude of the judges could cause a preclusion of further possibilities for the subject, who would end up interpreting the attitude of the institutions as a rejection or misunderstanding towards him, reversing the objectives of resocialisation re-education. According to Zandrini, Cavazza, \& Perduca (2019), juvenile deviance is often the reaction to real or presumed misunderstandings on the part of the adult world, which frequently shows indifference, mistrust and disaffection. The Judge may order the "suspension of the trial" and the "probationary period" when it is necessary to assess the juvenile's personality, as an alternative measure to detention. With the suspension order, the judge, therefore, entrusts the minor to the Juvenile Services of Justice Administration for observation, treatment and support in collaboration with the municipality services where the minor lives (Balducci \& Tre Re, 2016). Foster care to Social services provides for the drafting of an educational project that involves first the minor (who must give his consent), the family and the so- 
cial fabric. In addition, the judge may issue prescriptions aimed at repairing the consequences of the offence and promoting the reconciliation of the juvenile with the injured party (Ciambrone \& Esposito, 2019). After the suspension period has elapsed, the judge, taking into account the juvenile's behavior, the evolution of his or her personality, and the possible successful trial, declares the crime extinct. The trial is suspended for a period not exceeding 3 years in the case of offences for which the penalty is life imprisonment or imprisonment of not less than (in the maximum) 12 years. In other cases, for a period not exceeding 1 year (Bargis \& Buzzelli, 2019). According to Dettori (2020) in the Italian penal system, after the judge decides to assess the juvenile's personality, he delegates the Juvenile Social Services the observation, treatment and support tasks issues. Personality assessment is usually linked to the use of clinical instruments, psychiatric reports or psychological tests. Actually, such assessment, recurs throughout the period of suspension of the trial and is not only represented by clinical investigations (if necessary), since the juvenile's behavior is continuously observed by the Juvenile Services during the development of the intervention project, prompting the juvenile to mature and reflect on his/her life, on his/her future, on the disvalue of the antisocial and anti-juridical acts that the minor has committed. Ciaschini (2012), maintains that most of the cases of "probationary period" concern juveniles who have never experienced prison and there are very few cases in which the minor is taken to a Juvenile Criminal Institute (IPM) on protected custody and then put on "probationary period". The places where the minor will carry out "probationary period" can be the family home (Bove, 2018), if the minor has a suitable family background for a successful probation period, or the community, whether it is socio-educational or therapeutic. Barbero Avanzini (2010) points out that, in absence of a suitable family background or in any case in absence of a stable environment, the socio-educational community is the place where the minor lives during his recovery and maturation process, undertaking study, recreational, environmental, sports and sometimes welfare activities. The elaboration of the educational project responds to the need to intervene on a "deviant minor", who must be educated to social coexistence and respect for rules. According to Ferri (2013) the Juvenile Social Service Office in agreement with the judicial authority is, therefore, the body delegated to plan the educational project, modulating in the latter, the functions of help and control in relation to the minor's educational needs, procedural stages and background. Secchi (2019) argues that the Juvenile Social Service Office, in the function of its institutional order, refers to the principles enshrined in international and national legislation on the protection of minor's rights and, in particular, to the purposes of the juvenile criminal trial in order to:

1) Provide information to the Juvenile Judicial Authority on the personal, family and environmental situation of the minor, by means of a report;

2) Elaborate individualised project hypotheses, oriented to support the acquisition of responsibilities, which favour the construction of the minor's identity 
and his social inclusion;

3) Implement the measures of the Judicial Authority, actively supporting the minor and his family in every phase of the criminal proceedings; d) promote active connections with the system of territorial services, as a prerequisite for the construction of "operational spaces", shared by public and private subjects, which are oriented towards the enhancement of each organisation knowledge and skills in order to give adequate answers to the problems of minor offenders or those at risk of deviance; e) support the minor so that the law experience can be used by him/her as an opportunity to understand the seriousness of the crime and its meaning: the answer to the question "why did he do it" is never as simple as it may seem.

This can be the starting point for a process of growth and change:

- promote responsibility for one's actions and awareness of the consequences for oneself and for others;

- deepen self-knowledge, exploiting one's resources and potential, but also recognizing and facing one's limits and difficulties;

- support the minor in taking on, through a concrete commitment, some life tasks of his age in order to "grow up and mature";

- promote the possibility of being someone in society by learning to trust one's own reasons and to understand those of others;

- promote understanding, acceptance and sharing of social rules;

- promote prevention and awareness-raising projects on adolescent problems (therefore not only aimed at young people who have committed crimes), in collaboration with the local services;

- promote individualized intervention projects.

Finally, according to Codini, Fossati, Frego, \& Luppi (2019), the operational purposes of Juvenile Social Service Office are marked by:

1) The assistance and accompaniment of the minor at every stage of the criminal proceedings, guaranteed through the continuity of assumption of responsibility by the Social Worker identified by the Management of the Juvenile Social Service Office;

2) Unlimited listening empathy;

3) Clear information to the minor and the family by the Juvenile Justice System, as well as conditions of accessibility to the Juvenile Justice Services. The social worker explains to the minor the legal context and its reasons, "what he/she can and cannot do", the meaning of transgressions of rules imposed by the judge and possible consequences.

\section{Method}

The present statistical/comparative study (Agresti \& Finlay, 2015) conducted from October 2019 to November 2020, is aimed at gaining a general understanding of the effectiveness of the alternative measure to detention of "probationary period" granted to juvenile accused subjects, for re-education and re-socia- 
lisation purposes. This procedure, following the suspension of the juvenile criminal trial by the competent Courts, provides for the assumption of responsibility by the Juvenile Social Service Offices aimed at the fulfilment of the tasks entrusted by the Judicial Authority. The study is divided into micro-objectives: the first concerns the collection of data over the period 2010 to 2020, concerning (Figure 1) "Number of minors in Social Service Office care (Italian-male and female, foreigners-male and female"). The second micro-objective refers to the general category of offences committed by minors in 2020 and listed below: other crimes; administrative fines and penalties; crimes against the person; use of weapons; crimes against property; crimes against public safety; crimes against public faith; crimes against the State, other institutions and public order (Figure 2). The third micro-objective concerns the collection of data relating to the specificity of offences committed by juveniles in the year 2020 and provided for by the Italian Criminal Code: crimes against the person; beating; sexual abuse; stalking; intentional homicide; intentional bodily injury; proven violence; other crimes against the person; attempted intentional homicide; brawling; threatening (Figure 3). Finally, the fourth and last objective was to investigate, after the "probationary period" the percentages of juveniles, (over a period of 10 years from 2010 to 2020) who, followed by Social Service, complied with the re-education programme and which led to the termination of the trial, having achieved a positive result in terms of modification of their personality, awareness of previous experiences of deviance, positive future intentions of compliance with social and legal rules (Figure 4). Data processing was carried out using Matlab R2020b.

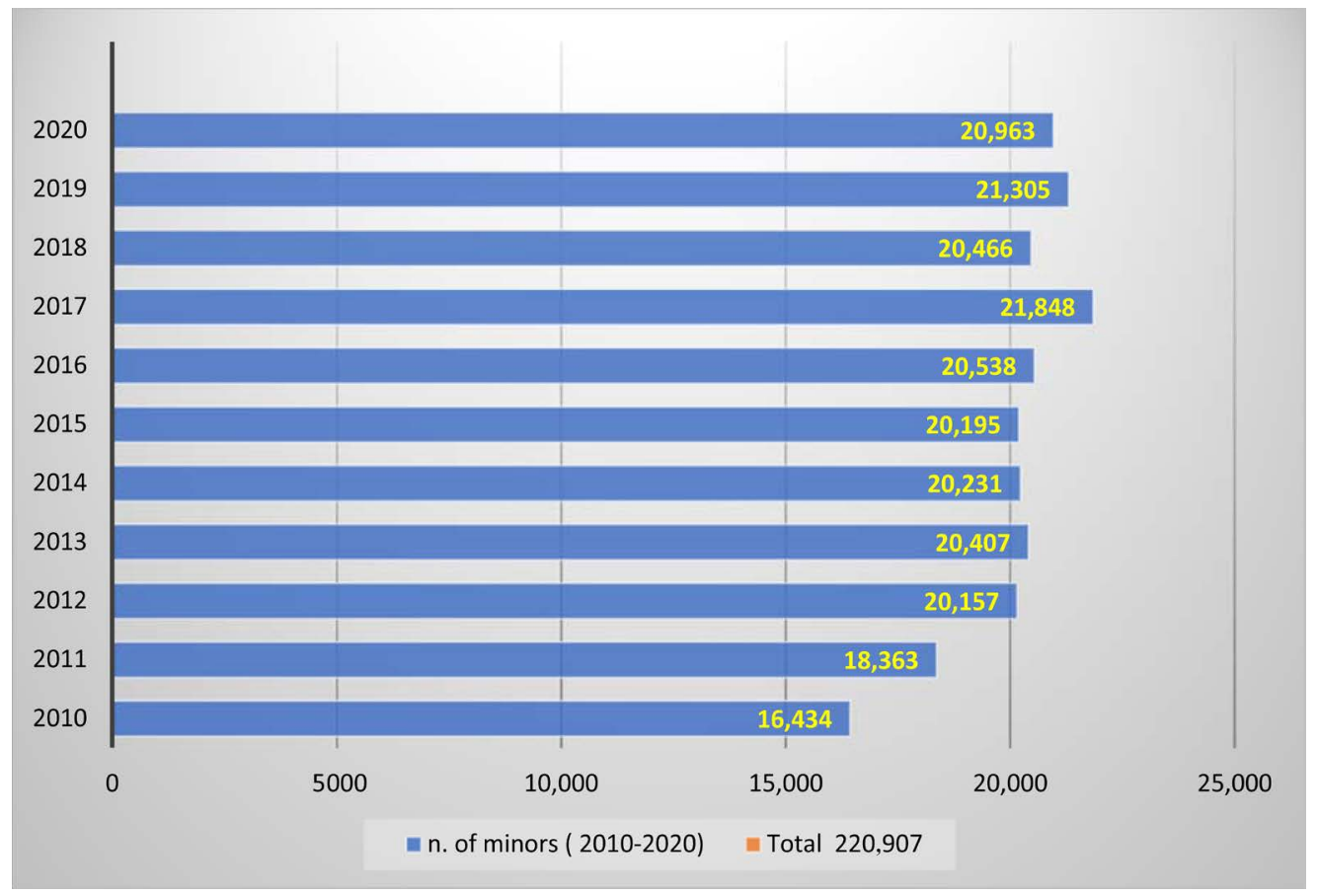

Figure 1. Number of minors in Social Service Office care (Italian-male and female; foreignersmale and female) in the years 2010 to 2020 (total No. 220,907). 


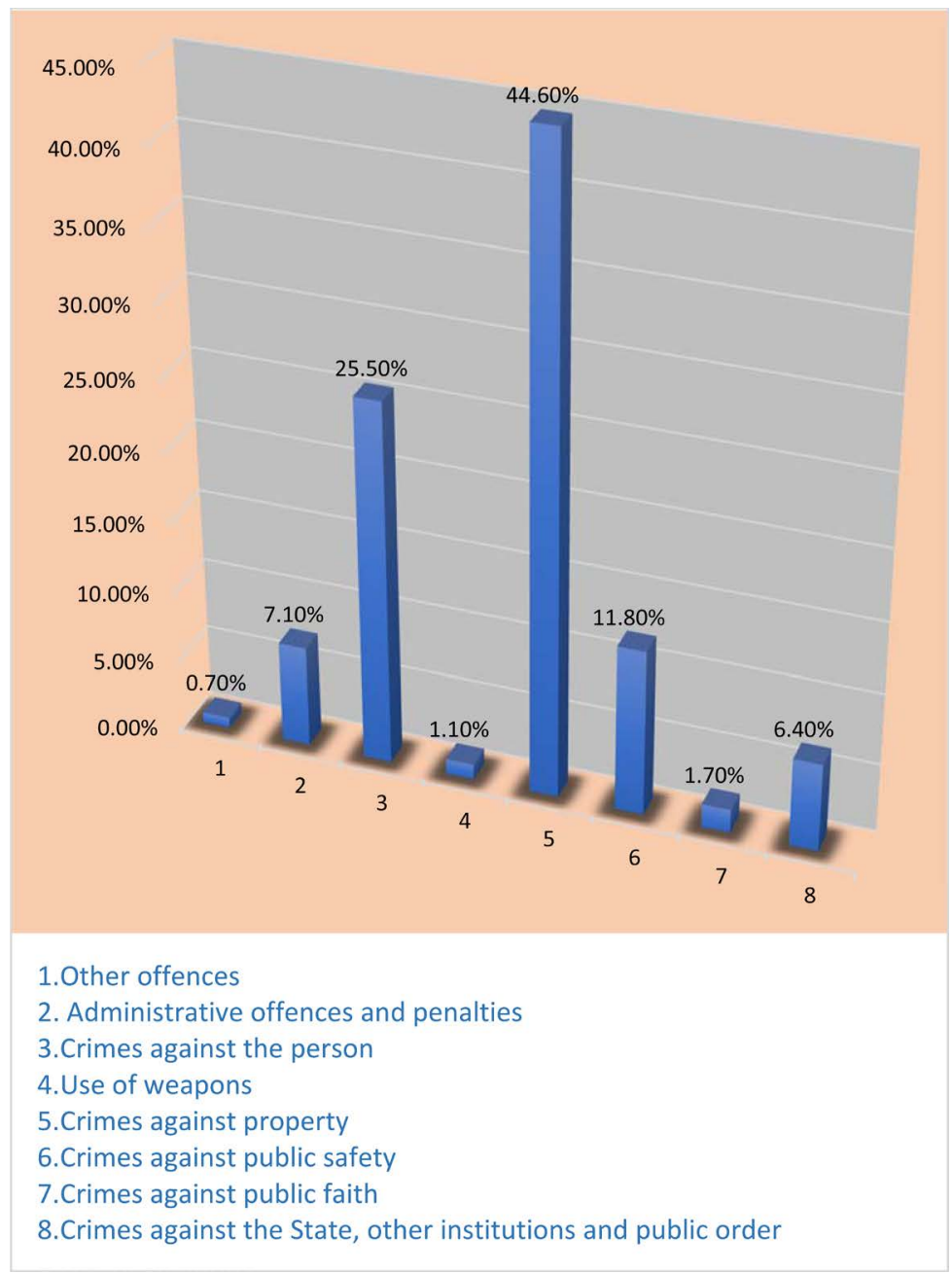

Figure 2. Offence categories (year 2020) of Italian juvenile offenders in charge to Social Service Offices.

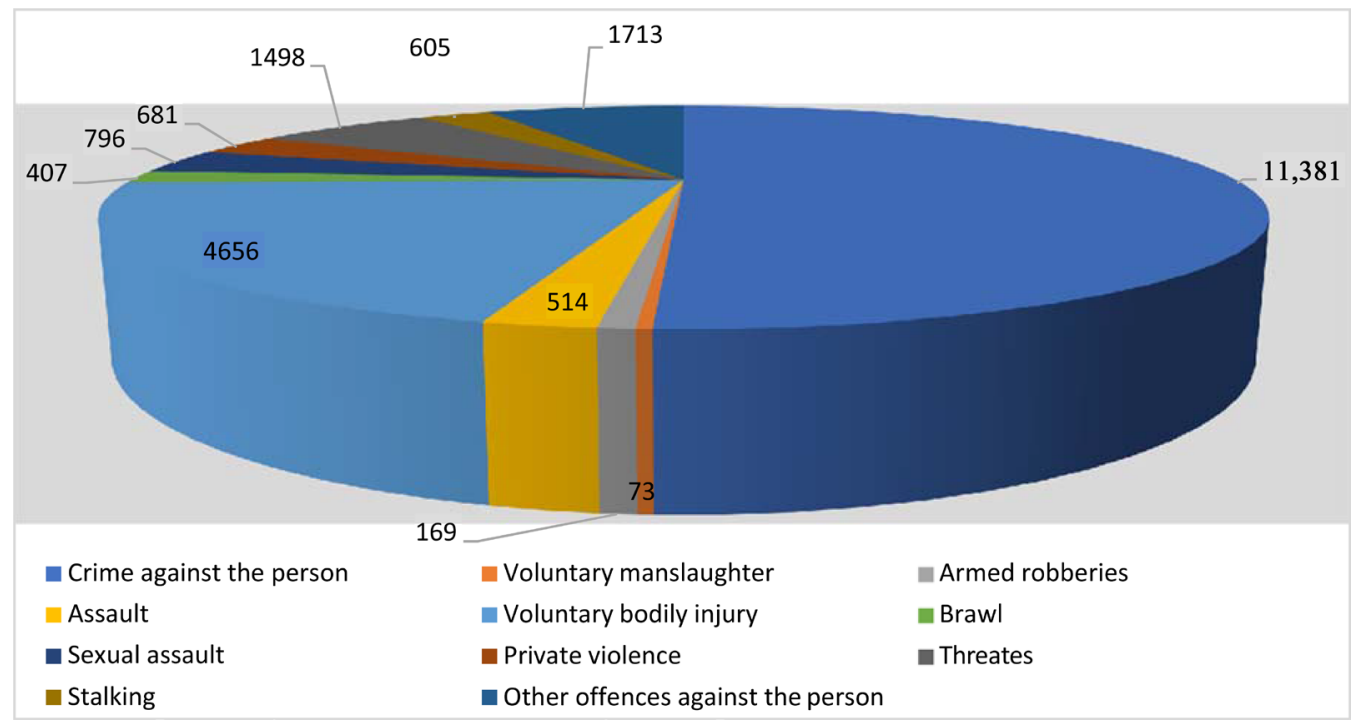

Figure 3. Specific types of offences (Year 2020) of Italian juvenile offenders in charge to Social Service Offices. 


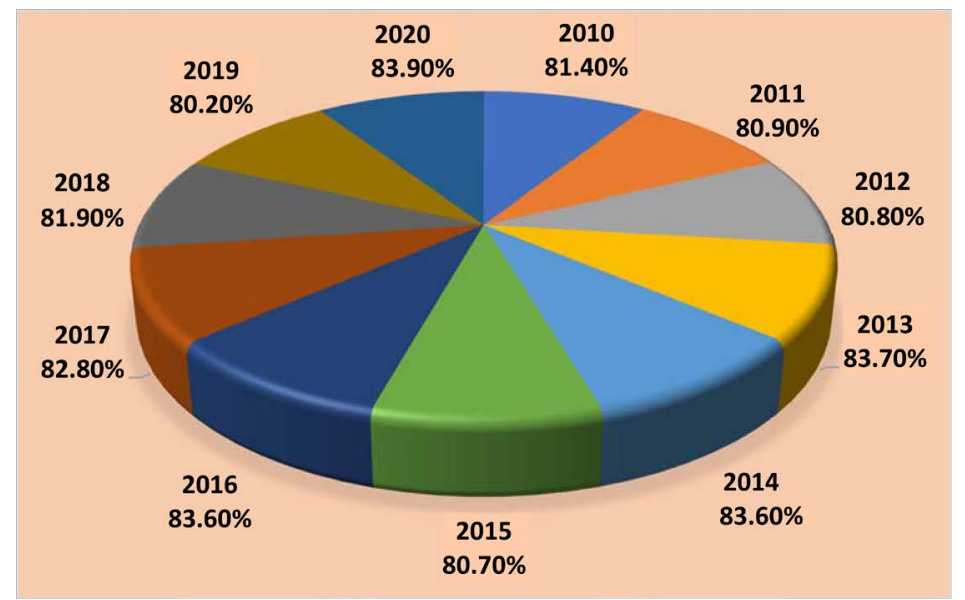

Figure 4. Positive outcome of "Probationary period" of juvenile offenders from 2010 to 2020.

\section{Results}

The study presented the following results: 1) a high number of Italian minors (male and female) and foreigners (male and female) in charge to the Juvenile Social Service Office of 19 Italian regions (Figure 1) from 2010 to 2020. The most significant data concern the years 2013 (20,407), 2014 (20,231), $2016(20,538)$, 2017 (21,848), 2019 (21,305), 2020 (20,963); 2) related to the general categories of offences committed by minors in 2019 (Figure 2), alarming data emerges with regard to the percentages of fines and administrative penalties for deviant behavior (7.10\%); crimes against the person (25. 50\%); crimes against property $(44.60 \%)$; crimes against public safety (11.80\%); crimes against the State, other institutions and public order $(6.40 \%) ; 3)$ related to the specificity of the crimes committed by minors in the year 2020 (Figure 3) significant numerical data emerges that relate to the commission by minors of crimes concerning: voluntary personal injury (4656); threats (1498); crimes against the person $(11,381)$; other types of crimes against the person (1713);4) finally, the study has detected the percentage of "positive outcomes" of probationary period in a time span from 2010 to 2020 (Figure 4) of the juvenile defendants who have followed the Juvenile Services Offices educational project, of (U.S.S.M.), extinguishing, therefore, the criminal trial and its effects. The percentages of positive outcome exceed $80 \%$ as the minimum average figure and reach the maximum figure of $83.90 \%$ in the year 2020.

\section{Conclusion and Limitation}

In the juvenile criminal process, two opposing needs coexist: on the one hand, that of sanctioning unlawful behaviors, on the other hand, that of safeguarding the deviant minor through means that help his reintegration into society, in order to avoid, above all, the danger of the reiteration of criminal behaviors. The present work wants to investigate, therefore, the effectiveness of the suspension of the trial and the relative "probationary period" of the minor offender. It is 
aimed at his recovery as an individual in society, through the collection and processing of data on the amount and types of committed crimes, as well as the outcomes of the re-educational process entrusted by the Judicial Authority to the Juvenile Social Service Office in Italy, where the role of the Social Worker becomes fundamental. The positive outcomes exceed $80 \%$ and demonstrate the effectiveness of the re-educational and re-socialisation process. However, the application of the "probationary period" as an alternative to imprisonment is not free from criticism. On the one hand, according to some, it represents, an opportunity for many young people to avoid prison, but on the other hand it highlights weak and problematic aspects. "Probationary period" is also used in cases of homicide and both serious and very serious violence, for which it is decidedly non-educative that after a "positive outcome" of the trial, the crime is extinguished. It would be appropriate, especially for very serious crimes, to close the criminal trial with the attribution of responsibility to the offender, and then possibly to proceed to the suspension of the sentence, but not of the criminal trial. The debate is still open today. This paper represents a small contribution in the youth crime landscape and cannot be considered exhaustive. It would, therefore, be appropriate for further research over time to provide updated data on the relationship between youth, justice and resocialization.

\section{Acknowledgements}

I would like to show many warm thanks to the Italian Juvenile Service Offices and the Ministry of Justice.

\section{Conflicts of Interest}

The author declares no conflicts of interest regarding the publication of this paper.

\section{References}

Agresti, A., \& Finlay, B. (2015). Basic and Advanced Statistical Methods for the Social Sciences. Upper Saddle River, NJ: Prentice Hall.

Balducci, M., \& Tre Re, L. (2016). Organisation of Social Services. Milano: Franco Angeli. Barbero Avanzini, B. (2010). Juvenile Justice and Social Services. Milano: Franco Angeli. Bargis, M., \& Buzzelli, S. (2019). Juvenile Criminal Procedure. Torino: G. Giappichelli. Bartoli, L. (2020). Suspension of Proceedings and Probationary Period. Padova: Cedam. Biarella, L. (2017). Juvenile Criminal Process. Milano: Altalex Editore.

Bove, V. (2018). Probation. Pisa: Pacini.

Caraccioli, L. (2018). Punishment and Security Measures. Juvenile Criminal Law. Code Reservation. Derogations from the Criminal Rules. Milano: Giuffrè.

Ciambrone, M. C., \& Esposito, M. (2019). Handbook on Restorative Justice and Juvenile Deviance. Cosenza: Edizione Santelli.

Ciaschini, U. (2012). Juvenile Social Work and Criminal Justice. Roma: Carocci editore.

Codini, E., Fossati, A., \& Frego Luppi, S. (2019). Handbook of Social Services Law. Torino: G. Giappichelli. 
D’Onofrio, E., \& Trani, A. (2011). Minors in Community. Welcoming, Effective Education and Professionalism. Roma: Aracne.

Dettori, F. (2020). Juvenile Justice and Social Integration. Milano: Franco Angeli

Di Tullio D’Elisiis, A. (2016). Probationary Period for the Accused. Milano: Maggioli Editore.

Ferri, A. (2013). Minor Protection in the Activity of the Local Social Service. Milano: Franco Angeli.

Giostra, G. (2016). The Juvenile Criminal Trial. Milano: Giuffrè.

Macrillò, A. (2018). Victim and Offender Minor. Criminal Offences, Sanctions and Procedural Treatment. Pisa: Edizioni Pacini Giuridica.

Randazzo, L., \& Galati, M.L. (2020). Probationary Period in Criminal Proceedings. Practical Applications and Defensive Strategies. Milano: Giuffrè.

Secchi, G. (2019). Minors Protection and Participatory Processes. Promoting Collaboration between Families and Social Services. Milano: Franco Angeli.

Senigaglia, R. (2020). Self-Determination and Minors. Itineraries of Juvenile Law. Pisa: Pacini Giuridica.

Zandrini, S., Cavazza, C., \& Perduca, R. (2019). Adolescent Offenders. The Psycho-Social Pathway in an Institutional Setting. Milano: Franco Angeli. 